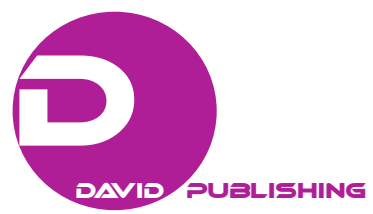

\title{
Domestic Living Space Furnishings, Culture Identity, and Media
}

\author{
Raghda Hassan Hareri \\ University of Edinburgh, Edinburgh, United Kingdom
}

\begin{abstract}
Consumption is an active process that engages the social world for individuals to make use of certain products. For many, the living room is the locus of product use, social activities, cultural values, and the personal narrative of the people who live in it. Consumers engage with their furniture in order for it to function effectively for them: It is thus used to furnish both the home and the self as well. Creating a certain living space with a particular use of furniture and interior decoration is the precise way in which the resident forms its arrangements, and builds a relationship with the surrounding objects in that living space. This activity, I argue, positions the residents in the process of presenting their personality characteristics and cultural identity. The Ethnographic approach is most appropriate methodology for research into such a personal area: the living room within the domestic environment. The topic of this research falls between different fields of studies including consumerism and media. This research reviews the influence of advertising in magazines and furniture shops on the meaning of living space design and how that encourages higher levels of consumption.
\end{abstract}

Keywords: domestic environment, furnishing and decoration, living space, residents, identity, culture, media, consumption

\section{Research Context}

This research entails a close analysis of the contemporary home environment-specifically living room furniture and its arrangement. The study of the home environment is a noteworthy trend in design studies, one which opens the boundaries of interior design to speak to a number of economic, social, cultural, and psychological factors of influence. My proposed research therefore investigates an as-yet unexplored avenue regarding the unique way by which interior arrangements and residential furnishings can present residents' personalities and cultural identity, by creating a certain living space with a particular use of furniture and interior decoration. The precise way in which the resident forms living space arrangements, and builds a relationship with the surrounding objects in that space, positions the resident in the process of presenting her/his personality characteristics and cultural identity. The aim of this research is to raise awareness of living room furniture as a sign of cultural identity in the context of Jeddah, Saudi Arabia, and to articulate how residents leave personality footprints on the space they inhabit. The research aims to demonstrate that interior design is more complex than simply shaping the use of a space, but also reinforces and presents the resident's personality and identity.

\section{Literature Review}

\section{Home Environment and Cultural Identity}

\footnotetext{
Raghda Hassan Hareri, interior \& product design, Edinburgh College of Art, University of Edinburgh.
} 
Hummon (1989) notes that the definition of identity involves an interpretation of both the qualities and the value of the self, characterized respectively as self-imagery and self-esteem. He argues that if one recognises the built environment and identity as both socially-constructed symbolic objects, the mutual relevance of the built environment for identity, and identity for the built environment, becomes clear. The extent to which dwelling and related domestic objects are used as symbols of identity by a culture, particularly for the construction of the self as a unique individual, is itself a social product.

This leads us to introduce two questions: Is there any specific way to create an identity in the home environment? How do residents express their identities within their home spaces? Sixsmith (1986) asserts that houses occupy the role psychologically, and are used to display aspects of identity in which people enjoy and express themselves. Furthermore, "Identity can be expressed in the home environment by people who have the ability to create certain composition from the collaboration of physical and social aspects" (Al-Naim, 1998, p. 18). The home reflects the individual's identity by the fact that "the design, the meaning, and the use of dwellings are intimately related to a range of cultural and psychological dimensions" (Abu-Ghazzeh, 1997, p. 256). Yasser Adas (2001) asserts "the house expresses or ought to express the inhabitants' values and attitudes through its form, style and decoration, interior and exterior" (p. 122). The consensus reached here is important and of great interest to this research. The understanding and investigation of how home spaces function to translate the identity of the occupants focusses on the meaning of a person's life, which is encapsulated in values and attitudes expressed in the built environment. The study of home use is thus related to a range of cultural and psychological dimensions, through home form and interior decoration, to express the inhabitant's sense of identity. As the home environment is one way by which people attempt to distinguish themselves from others and express their identity, this paper investigates how Saudi home spaces and interior design can (quite literally) speak words and present meanings and address the identity of its inhabitants. As Jin (1993) states, "Home occupies a psychological role and is used to display aspects of identity. People enjoy the opportunity for self-expression. They attribute meanings to domestic space and show their values and creativity in decorating the front of their houses" (Cited in Al-Naim, 1998, p. 80).

A home environment is a cultural phenomenon.

Home can be understood as an emotional investment that a person makes in a particular place, which may be reinforced by repeated, ritualized ways of being. As I have argued, notions of home are both deeply personal and are inextricably bound up in cultural and historical contexts. (Jones, 2007, p. 59)

The material culture of the home can be used to examine realizations of the self by focusing on the self-creation of the subject through interaction with the object in what Miller calls the process of objectification (Miller, 2001). Further, Stone draws attention to a distinctly perceptual nature of material culture that "The realm of material culture can be seen to constitute cultural maps of meaning in which social beings interact. For example, each item of furniture in a room has value and is integral to the construction of meaning" (Stone, 2006, p. 54).

The home pictures the individuality of its residents and "their personal identity as individuals and as a family, along with their ties, bonds, and affiliations with the community and larger culture of which they are a part" (Abu-Ghazzeh, 1997, p. 250). Similarly, Janes (1992) states

Designs and lifestyles can be seen as resulting from sets of choices among many alternatives. These choices reflect certain ideal images and schemata. This process results in sets of cues which are "encoded" in the environment. People 
establish cultural codes based on their experience and background. Home owners give expression or encode their home front with messages that are symbols of themselves and their cultural codes. (Cited in Abu-Ghazzeh, 1997, p. 258)

Rapoport mentions "the house is an institution, not just a structure, created for a complex set of purposes. Because building a house is a cultural phenomenon, its form and organization are greatly influenced by the cultural milieu to which it belongs" (1969, p. 46).

In this context, culture and home environment are strongly interrelated with each other as the home environment is the predominant place in which cultural values are expressed intensively. Identity comes from the culture and environment in which one lives and experiences all the time; it is not ingrained in him or her as a human being. "Identity is not something given to society, but it is something that should emerge from the interaction between individuals and groups in society and between the whole society and the surrounding physical objects" (Al-Naim, 2008, p. 144). Furthermore, "to develop identity there has to be a common ground, a common space to share, and a homogeneous group of people to interact" (Mahmud, 2007, p. 42). Identity is therefore not static and unchanging; rather, it is variable regarding to changes to the cultural core of society. "Identity, similar to other social phenomena, may change over time, which means that each generation will express its identity from its own perspective" (Al-Naim, 2008, p. 143). From this thought, we can consider that peoples' identity is expressed through their culture and living environment. In the home environment, Al-Naim states that

the concept of identity should be seen from three main aspects: Physical aspects where the perceptual communications are manifested through objects which people make and use, social aspects by which people produce and mobilise meanings, and finally temporal aspects where the meanings of things continue in individual and collective memories. (Al-Naim, 1998, p. 92)

Akbar contends that "the identity that people need to convey to others is a strong cultural reason for the existence of objects" (1998, p. 28). Verwijnen (2000) believes that

objects imply a meaningful status to a material culture, which are implicit in our social interaction: Theses man-made things are appropriated into our culture in such a way that they represent the social relations of culture and carry values, ideas and emotions. (cited in Mortezaei , 2007, p. 84)

Sparke states

Domestic furniture is one of the richest elements in our material environment. It is part both of our heritage and of our everyday surroundings, and it seems likely that it will always continue to play an essential role in our society and culture. (Sparke, 1986, p. 106)

Cultural identity can be expressed in the home environments by the inhabitants, who have the ability to create certain combinations of physical, social, cultural, and psychological aspects through their interaction with the surrounding physical objects in the domestic space. We can argue that individuals are therefore creators of identity and spaces. This process of identity construction results in sets of cultural values that are encoded in the home environment by inhabitants and that give expression based on those inhabitants' experience, attitudes, values, and conceptions of behavior as symbols of themselves. The home space designs are influenced by the cultural values to which it belongs, so domestic objects can thus be used as symbols of cultural identity: They shape identity through visualising cues in a space, so that by creating a certain living space with furniture and interior design one can see the cultural characteristics and identity of residents living a 
certain life through the objects that residents use. In this sense, it can be argued that cultural values play a vital role in enhancing and consolidating residents' identity in their home environment. This leads us to ask: Can we identify those cultural values which have played an essential role in the formation of identity within the contemporary houses in the city of Jeddah? To what extent are Saudi cultural values supported by contemporary living room furniture?

\section{Resident Personality within Domestic Spaces}

In this section, I investigate how domestic spaces and furniture become a major vehicle for displaying the image of resident personality and identity. According to Douglas and Isherwood (1979), "the uses of goods are social, and carry social meanings. For this reason, it is possible to read the person's life and personality, and place in society from the goods" (cited in Kandiyoti \& Saktanber, 2002, p. 295). Cieraad asserts that "We still express ourselves symbolically in the spatial arrangements and decorations of our houses and the surrounding public space" (Cieraad, 1999, p. 2). Despres says "Placing objects with special meaning or specific aesthetic properties within or around the home, arranging the furniture, as well as maintaining the home are all territorial behaviours most often referred to as personalization" (1991, p. 99). Furthermore, Csikszentmihalyi and Rochberg-Halton note the relation between household objects and personality: "That interaction with objects alters the pattern of life. It is also relatively easy to admit that the things people use, own, and surround themselves with might quite accurately reflect aspects of the owner's personality" (Csikszentmihalyi \& Rochberg-Halton, 1981, p. 14). Accordingly, as Douglas and Isherwood stated that goods in general present the residents' life and personality, so we can say that goods such as furniture and decorative elements in the context of the domestic environment also present people's life and their personality. This is in addition to what Cieraad and Despres assert, that it is not just the goods in themselves which express residents' personalities but also the arrangement and decoration of the residential space itself. Csikszentmihalyi and Rochberg-Halton support the view that household objects and the arrangements of these objects in the living space express residents' personality by asserting that it is also the interaction between residents and the household objects that surround them and are used by them, which indeed present their personalities. It could be seen that through the living space furnishing and decorating, the personality and pattern of life for the space inhabitants could be presented, so that by creating a certain living space with a particular use of furniture and interior decoration, the way in which resident forms its arrangements, and builds a relationship with the surrounding objects in the living space, positions the resident in the process of presenting her/his personality characteristics and identity.

\section{Consumption and Media}

Michael Dietler defines Consumption as "a material social practice involving the utilization of objects (or services), as opposed to their production or distribution" (Hicks \& Beaudry, 2010, p. 209). Consumption is taken to be an active process that engages the social world to make use of certain products. The term "consumer culture" refers to the phenomenon of objects playing such a role in the contemporary society that they form a stylistic self-consciousness on the part of the buyer-user. The new objects create and shape consumer culture through both a projection of a lifestyle and a display of individuality. This stylistic self-consciousness is not centered on the taste of clothes to the same extent to which it covers the home and its furnishings and decoration. Consumers must engage with their furniture in order for it to function effectively for them: It must be used to furnish certain aspects of the home and the self as well. As Grant McCracken (2005) stated in his study of culture and consumption "objects give their consumer access to cultural principles such as gender, 
class, age, personality, and lifestyle" (p. 109).

The consumption of visual media such as "newspapers, magazines, catalogues, television, and even the internet are part of the global marketplace where people now shop for the latest houses, furnishings, and ideas and values regarding home and family life" (Birdwell-Pheasant \& Lawrence-Zuniga, 1999, p. 27 cited in Miller, 2001, p. 24). Roberts and Maccoby (1985) assert that mass media influences human behaviour and what "gratification" people received from media exposure. The bullet theory, which espouses that the mass media can elicit immediate responses on the part of viewers from exposure to media messages, underlines this suggestion that mass media can and does exert a powerful effect on its audiences (cited in Merdad, 1993). Moreover, "Since the mid-1980s, the media coverage of design has seen a dramatic increase across television programs, newspaper columns, published books, magazines, and websites" (Miller, 2009, p. 34). Furthermore, "the media obsession with novelty encourages us to expect shorter life spans from our furniture, and to change our interiors much more frequently than in the past" (William, 2006, p. 151). The powerful influence of such a process drives my research to study the influence of commercial buying: The dramatic movement to modern furniture within Jeddah living space and how the consumer-driven power of advertisements on furniture magazines with glossy press and furniture trade fairs spreads the new lifestyle of contemporary furniture as people are confronted with advertisements.

In the same way in which advertisements affect and influence consumers, the furniture store plays a parallel significant role in enabling furniture shoppers to communicate with furniture by trying out and experimenting with different furniture styles and, indeed, lifestyles through displaying the furniture with the use of artificial, ready-made room sets. Many furniture shops make use of this interesting method of displaying furniture via maze rooms to display a wide variety of models and lifestyle options. Meanwhile, the Internet commerce industry has developed rapidly in recent years. As customers are able to purchase a product from a merchant's website and have it delivered directly to their house, rather than having to go physically to a store to purchase a product and transport it home. In fact, the Internet is used for more than merely ordering products. Customers rely on the Internet to obtain information that influence purchasing decisions. For instance, online reviews and "blogs" are an important source of such information and lifestyles.

\section{Globalisation and Cultural Identity}

In a globalised view, the modern social life introduced across the globe the opportunity to live-in a way - in the same time and space. When new ways of life are spread across different countries, they can create shared ways of life and ideas without any boundaries. Globalisation has the effect of diminishing the local identity and social life of any particular country, and giving rise to new and shared identities. Meanwhile, some researchers believe that globalisation does not destroy the cultural identity while they support the cultural diversity and disseminates it globally. The global has become commonplace. In this regard, Marzano (1999, p. 74) states:

Although we see evidence on the globalisation of culture all around us, ethnic diversity is still alive and well, and with a great future ahead of it. We shall increasingly use it to express not only our ethnic origins but also our own unique identity and through it achieve a measure of self-fulfillment [...] Globalisation and greater mobility are making people more aware of other cultures. People are now cherry-picking from a whole array of behaviour allegiances. The more our societies become multicultural and the more we see of what there is in the world, the stronger becomes our desire to experience it all. (cited in Mortezaei, 2007, p. 50)

At this point, globalization becomes a problem from the cultural identity perspective. Whereas, I believe 
that globalisation does not destroy the cultural identity because it helps grow awareness on the local level to protect cultural identity and cultural diversity. Globalisation can be seen to encourage people to search for their local knowledge, maintaining their distinctive set of cultural beliefs, practices, and values in order to strengthen their cultural identity. The global citizen could be seen as a person who can act locally but think globally, who keeps an eye on maintaining cultural identity while participating in the benefits of globalization. It could be argued that cultural identity can be strengthened through globalization by providing the means to support cultural groups attempting to make a difference in society while still maintaining their distinctive set of cultural values, ethnic roots, and religious beliefs. These factors have accumulated for hundreds of years and formed the pattern of the cultural identity of many societies. No matter how much globalization changes peoples' awareness, the truth is the roots of the identity of any society and culture will not change in the extreme. In the similar vein, Wang states that "in the new era of globalization, people become much more concerned about the uniqueness and particularity of their own culture. Cultural identity provides the global significance of local knowledge and the sense of self, community and nation" (2007, p. 83).

In many cases, furniture and global products may not be attuned to any local culture, whereas local residents may cherish their own cultures and desire to ensure its continuity via the interior design of their home environment. Yasser Mahgoub (2004) supports Wang's view in asserting, "People are eager to enjoy the luxuries of modern life that they can afford to have while at the same time retaining a cultural identity and satisfying special social requirements" (p. 516). Wang (2007) adds, "People are not mere objects of cultural influences, but subjects who can sift various influences and reject or integrate them. Sometimes, advocates of anti-globalization overlook the power of people's subjectivity" (p. 84). Akbar asserts,

People do not become passive if massive transformation takes place. This is because they always need to make sense of their surroundings, understand situations, define roles, perceive settings and objects, and test the compatibility of these objects with their values and use of space so that the complex image of everyday life is simplified and put into order. The cultural process of filtering objects continues. (1998, p. 199)

\section{Research Methodology}

\section{Coding and Observing the Living Space Features}

The items and contents of the domestic living rooms under study are coded by the Personal Living Space Cue Inventory (PLSCI) that was developed by Gosling et al. (2005) as an instrument designed to document, comprehensively, features of personal living spaces to link the living room furnishing and decorative items with the personality characteristics of the people who use those rooms (Gosling et al., 2005a; Gosling et al., 2005b).

\section{Personality Measures}

In this research, Self-report is used to measure the personality of residents in their living space. The personality traits of residents were explored by using the BFI personality inventory that is based on the Five-Factor Model.

\section{Interview and Photographs}

In order to ascertain the residents' identity within any residential living space, it is very important to understand the physical characteristic and meaning of this living space by using an interview technique. The participants tell the story of furnishing and decorating their living spaces by describing furnishing items and process, the activities carried out in the living space, and their multiple uses. In addition to the interviews, photos and videos have been taken of the living spaces to capture their architecture, interior design, floor-plan, 
furnishing, and decorative elements.

\section{The Case Study}

\section{Jeddah City and Its Residents}

Saudi Arabia citizens are attracted by the modern lifestyle that plays upon the theme of a "new", "better", and "improved" life. Society has demonstrated an eagerness to buy new furniture in order to follow the flow of contemporary lifestyle interiors. As the oil boom and the increase of the Saudi economy and wealth expanded the possibility for opening shops and importing a wide variety of goods from abroad, possibilities opened for society to purchase what they have seen in the furnishing market to modernise their home environment. Furniture became the tool that tested people's settledness and affluence and defined the visual material culture of the age.

In approximately the last 20 years, Jeddah has experienced one of the most rapid and massive modernisations in human history. One of the modernisation's elements is the modern home, widely understood to be a site of deep social change, reflective of attempts to cultivate self-consciously modern lifestyles that are affected by the wheels of change towards modernisation. As it is understood that consumption becomes a larger element in the standard of living in the city, so the contemporary Jeddah culture relies on the most expensive mechanical, electrical equipment and fashionable furniture to furnish the living homes.

The Saudis are using their houses as symbols of their affluence and status in society. The categories of class and their position in society, their image and how society views them-where one lives, one's occupation and status, one's home design and its furnishings - these concepts influence the Saudi residents and lead them to follow the modern furniture movement to furnish their homes with a fashionable style. Ostentation has entered the culture to become an image of the successful, respected lifestyle.

\section{Conclusion}

The discussion of this paper has focused on the role furnishings play with respect to shaping the space used for living, as well as how furniture and interior arrangements in particular accommodate the personality and identity of its resident. This paper aimed to demonstrate that living space furnishings not only have a unique ability to shape the use of a space but also reinforce and shape the resident's personality and cultural identity.

It is therefore important to establish a methodology that is highly workable within this current research setting, to fill the gap in the existing research, and to accomplish the overarching research aim regarding the influence of furniture on the contemporary living room. This research develops a comprehensive methodology to shape the most complete, accurate, and useful portrait of residents' personality and identity within living spaces. It proposes therefore an analytic framework that can be developed or adjusted in future research to provide a better understanding of the relationship between objects, spaces, and people.

The aim of this research has been to promote a cultural awareness regarding the furniture and interiors of Jeddah's home environment as sign of resident personality and an image of wider cultural identity. Accordingly, this research is intended to analyse the variety of residents' personalities as presented through furnishing and decorating the domestic living spaces in Jeddah and presenting the image of their cultural identity. 


\section{References}

Abu-Ghazzeh, T. (1997). The dialectic dimensions of homes as an expression of identity and communality in Amman, Jordan. Housing Studies, 12(2), 247-263.

Adas, Y. (2001). Change in identity of Saudis' built environments: The case of Jeddah (unpublished PhD thesis). Heriot-Watt University, Edinburgh College of Art.

Akbar, S. (1998). Home and furniture: Use and meaning of domestic space, Jeddah, Saudi Arabia (unpublished PhD thesis). University of Newcastle upon Tyne.

Al-Naim, M. (1998). Continuity and change of identity in the home environment: Development of the private house in Hofuf: Saudi Arabia (unpublished PhD thesis). University of Newcastle upon Tyne.

Al-Naim M. A. (2008). Identity in transitional context: Open-ended. Archnet-IJAR, International Journal of Architectural Research, 2(2), 125-146.

Cieraad, I. (ed.) (1999). At home: An anthropology of domestic space (First Edition). New York: Syracuse University Press.

Csikszentmihalyi, M., \& Rochberg-Halton, E. (1981). The meaning of things: Domestic symbols and the self. Cambridge: Cambridge University Press.

Despres, C. (1991). The meaning of home: Literature review and directions for future research and theoretical development. The Journal of Architectural and Planning Research, 8(2), 96-115.

Gosling, S., Craik, K., Martin, N., \& Pryor, M. (2005a). Material attributes of personal living spaces. Home Cultures, 2(1), 51-88

Gosling, S., Craik, K., Martin, N., \& Pryor, M. (2005b). The personal living space cue inventory: An analysis and evaluation. Environment and Behavior, 37(5), 683-705

Hicks, D., \& Beaudry, M. (2010). The Oxford handbook of material culture studies. Oxford: Oxford University Press.

Hummon, D. (1989). House, home and identity in contemporary American cultures. In E. Chambers and S. Low (Eds.), Housing, culture and design. Philadelphia: University of Pennsylvania Press.

Jones, E. (2007). Spaces of belonging: Home, culture and identity in 20th-century French autobiography. Amsterdam-New York, Rodopi B. V.

Kandiyoti, D., \& Saktanber, A. (eds.) (2002). Fragments of culture: The everyday of modern Turkey. London: I. B. Tauris \& Co Ltd.

Mahgoub, Y. (2004). Globalization and the built environment in Kuwait. Habitat International, 28, 505-519.

Mahmud, S. (2007). Identity crisis due to transformation of home environment: The case for two Muslim cities, Dhaka and Hofuf. METU JFA, 24(2), 37-56.

McCracken, G. (2005). Culture and consumption II: Markets, meaning, and brand management. Bloomington: Indiana University Press.

Merdad, A. (1993). Foreign television programs and their sources: An empirical analysis of media usage and perceptions of its effects by young viewers in the Kingdom of Saudi Arabia (unpublished PhD thesis). Wayne State University.

Miller, D. (ed.) (2001). Home possessions: Material culture behind closed doors. Oxford: Berg.

Miller, D. (2009). The comfort of things. Cambridge: Polity Press.

Mortezaei, S. R. (2007). Culture rich design: A "Cultural-Semiotic" framework in product design applied to urban streetscape elements (unpublished $\mathrm{PhD}$ thesis). University of Brighton.

Rapoport, A. (1969). House form and culture. Englewood Cliffs, N. J., Prentice-Hall, INC.

Sixsmith, J. (1986). The meaning of home: An exploratory study of environmental experience. Journal of Environmental Psychology, 6, 281-298.

Sparke, P. (1986). Furniture: Twentieth century design. Twentieth Century Design. E. P. Dutton.

Stone, T. T. (2006). Cultures of consumption within residential care homes: Understanding elderly bricoleurs' cultural maps of meaning (unpublished PhD thesis). University of Stirling.

Wang, Y. (2007). Globalization enhances cultural identity. Intercultural Communication Studies, XVI(1), 83-86

Williams, G. (2006). The furniture machine: Furniture since 1990. London: V \& A Publications. 